\title{
ENDOPRÓTESE REVESTIDA DE JUGULAR PRESERVADA DE BOVINO: ESTUDO COMPARATIVODA RESPOSTA TECIDUAL EM AORTA TORÁCICA DESCENDENTE E VEIA CAVA INFERIOR DE SUÍNOS
}

\author{
BOVINE PRESERVED JUGULAR COVERED STENT-GRAFT: COMPARATIVE STUDY OF \\ TISSUE RESPONSE AT SWINE THORACIC DESCENDENT AORTA AND INFERIOR VENA \\ CAVA
}

\author{
Celso Luiz Muhlethaler Chouin, ACBC-RJ' ${ }^{1}$ Cristina Ribeiro Riguetti Pinto ${ }^{2}$; \\ Gaudencio Espinosa Lopez, TCBC-RJ ${ }^{3}$
}

\begin{abstract}
RESUMO: Objetivo: Avaliar e comparar a resposta tecidual de uma endoprótese biosintetica implantada na aorta torácica descendente e veia cava inferior de suínos. Método: Foi implantada uma endoprótese auto-expansível composta de aço inoxidável, revestida por veia jugular de bovino, processada pelo método L-hydro, com auxilio de uma bainha de liberação Taheri-Leonhardt (Flórida, EUA) na aorta torácica descendente, e a veia cava infra-renal de 10 suínos. Sessenta dias após, as endopróteses foram retiradas e analisadas sob o ponto de vista macro e microscópicos. Foram observados: perviedade, grau de incorporação a parede do vaso, tipo de reação inflamatória, e local de maior resposta, tanto em relação a camada do vaso quanto ao local de contato com o anel de aço Resultados: Todas as endopróteses encontravam-se pérvias, e incorporadas à parede. No setor venoso, seis apresentaram traves fibrosas em sua luz, e quatro apresentaram fibrose perivascular. No setor arterial somente uma prótese apresentou discreta estenose, sem fibrose perivascular. A reação inflamatória crônica tipo corpo estranho ocorreu em $100 \%$ das peças, a camada média foi a mais acometida no setor venoso, enquanto a íntima foi mais constante na artéria, o grau de incorporação foi mais firme na veia em comparação a artéria. A reação tecidual mostrou maior tendência nas áreas em intimo contato com o anel de aço (intraanelar), mais intensa na artéria do que na veia. Conclusão: A prótese apresentou baixa trombogenicidade em ambos os sistemas, houve maior reação tecidual e baixa biocompatibilidade no setor venoso (Rev. Col. Bras. Cir. 2008; 35(4): 252-258).
\end{abstract}

Descritores: Implante de prótese vascular; Contenedores; Veias jugulares; Veia cava inferior/cirurgia; Aorta torácica/cirurgia; Desobstrução vascular; Teste de materiais; Bovinos/cirurgia; Suínos/cirurgia; Estudo comparativo.

\section{INTRODUÇÃO}

O objetivo de promover a revascularização efetiva, ou temporária até a neovascularização na área além do processo obstrutivo levou a elaboração de novas e revolucionárias técnicas. Entre estas fazemos referencia especial às técnicas minimamente invasivas, os procedimentos intraluminais de angioplastia por balão e os implantes de stent, que ofereceram alternativas mais seguras aos pacientes com graves comprometimentos clínicos. As vantagens indiretas dos Stents são: pouca invasividade, baixo período de internação, melhora clínica imediata, ampla utilização em pacientes de alto risco cirúrgico, além de permitir re-intervenções. As vantagens diretas são: evita o trauma direto no vaso envolvido, menor perda de sangue, previne o hematoma perivascular e a síntese acontece em locais não comprometidos do vaso ${ }^{1-4}$.

No circuito venoso a angioplastia percutanea pode ser eficaz durante alguns meses, porém geralmente as estenoses são muito resistentes e há um alto índice de reestenose a curto prazo de tempo ${ }^{5}$. A maior parte dos pacientes, com exceção dos casos de tratamento paliativo em doença neoplásica, terá de se submeter a vários procedimentos endoluminais e, mesmo assim, os resultados ainda são inferiores aos do circuito arterial ${ }^{5,6}$.

Alguns autores propuseram uma cobertura sob ou sobre as estruturas metálicas, entretanto, não há ainda um tipo de material considerado ideal para este objetivo ${ }^{3,7,8}$. Três materiais sintéticos são os mais utilizados nos dispositivos recobertos: Politetra-fluoroetileno expandido (ePTFE), Polietileno terephtalato (PET) e Poliuretanos ${ }^{9}$.

Vários processos celulares estão envolvidos na cicatrização das endopróteses e são os reflexos da resposta tecidual conseqüentes ao implante de um corpo estranho no sistema circulatório. São quatro os tipos de reação tecidual: 1) formação de trombo; 2) crescimento de neointima; 3) endotelização do dispositivo; 4) formação de infiltrado de células inflamatórias ${ }^{10,11}$. A extensão e a magnitude das respostas celulares estão relacionadas ao local do implante da

1. Doutor em Medicina pelo Programa de Pós-Graduação em Medicina (Cirurgia Geral) - Faculdade de Medicina - Universidade Federal do Rio de Janeiro - UFRJ.

2. Mestre em Medicina pelo Programa de Pós-Graduação em Medicina (Cirurgia Geral) - Faculdade de Medicina - Universidade Federal do Rio de Janeiro - UFRJ.

3. Professor Adjunto do Departamento de Cirurgia Faculdade de Medicina da Universidade Federal do Rio de Janeiro - UFRJ.

Recebido em 26/02/2008

Aceito para publicação em 04/04/2008

Conflito de interesses: nenhum

Fonte de financiamento: nenhuma

Trabalho realizado no Centro de Pesquisas da Labcor Laboratórios - Santa Luzia - MG. 
endoprótese, tipo e geometria das hastes de metal do stent, tipo de revestimento, sua estrutura e porosidade 9 .

Fez-se o presente estudo para avaliar comparativamente a resposta tecidual de uma nova prótese biosintética auto-expansível, revestida por um segmento de veia jugular de bovino processada pelo método L-hydro quando implantada na aorta torácica descendente e veia cava infra-renal de suínos.

\section{MÉTODO}

O objeto em estudo neste trabalho é um dispositivo manufaturado com material biológico e sintético. A parte biológica é composta por um fragmento não devalvulado de veia jugular de bovino abatido em idade adulta. A parte sintética é composta por três anéis e uma haste de conexão, ambas feitas de aço inoxidável 316L, com 0,018" de secção redonda além de memória para auto-expansão. Cada anel, em forma de ziguezague com 10 dobras eqüidistantes, cinco cristas e cinco vales, apresentava como dimensões médias: 12 mm de comprimento e 17,65 mm de diâmetro. Convencionamos denominar "área intra-anel" a área de contato direto do revestimento com o anel, e área "inter-anéis" a área entre dois anéis contíguos. A média do comprimento total dos dispositivos introduzidos na aorta era $69 \mathrm{~mm}$ (variando de $53 \mathrm{~mm}-80$ $\mathrm{mm}$ ) de extensão, e a média dos diâmetros foi $19 \mathrm{~mm}$ (variando de $16 \mathrm{~mm}-22 \mathrm{~mm}$ ). Na veia cava, a média do comprimento total dos dispositivos introduzidos era $63.1 \mathrm{~mm}$ (variando de 47 mm-80 mm) de extensão, e a média dos diâmetros foi 16 mm (variando de 10mm-20mm). Os diâmetros dos dispositivos introduzidos em cada animal foram estipulados pela avaliação aproximada do diâmetro do vaso obtido na angiografia prévia adicionada de aproximadamente de $10 \%$ do total. As jugulares bovinas foram obtidas em abatedouro aprovado pelo Ministério da Agricultura e Vigilância Sanitária. Após o abate de animais com idades variando entre 30 e 60 meses. As veias foram limpas, adequadamente seccionadas, suturadas internamente ao arcabouço metálico com fios de poliéster 7.0 (Ethicon, Inc, EUA) ${ }^{\circledR}$ e tratadas pelo método Lhydro (Figura 1). O processo L-Hydro consiste de três etapas: 1- Extração de substancias antigênicas teciduais, sem o uso de detergentes, surfactantes ou enzimas digestivas, com mascaramento dos antígenos remanescentes sob oxidação química controlada pelo acido polietilenoglicol. Nesta etapa utilizaram-se condições físicas especificas para proteção dos componentes extracelulares tais como colágeno e elastina; 2- Incorporação de um agente antiinflamatório não esteróide ( aspirina) e de um agente antitrombótico (equivalente a heparina) ao tecido. 3- A ultima fase, consistiu na esterilização do tecido em fase aquosa de peróxido de hidrogênio (H202).Foi utilizado o sistema liberador da endoprótese de aorta tipo Taheri-Leonhardt (Medthronic, Flórida EUA) ${ }^{\circledR}$ para implante do dispositivo. Este sistema é composto por uma bainha coaxial e por um êmbolo propulsor. Os sistemas utilizados variaram de 18 a $24 \mathrm{Fr}$. A escolha do calibre do sistema de liberação foi baseada na regra do " $n+4$ " desenvolvida in vitro por Gómez-Jorge et cols ${ }^{12}$.

Foram utilizados dez suínos de raça híbrida (cruzamento de landrace e Large White), provenientes da Fazenda
Córrego Fundo, Brumadinho, M.G. Todos do sexo feminino com idade média de três meses, e peso inicial aproximado de $25.4 \mathrm{~kg}$, variando de $20 \mathrm{~kg}$ a $35 \mathrm{~kg}$. Os animais foram alimentados com dieta padronizada, ração de crescimento para suínos CEVADIL 12 - 600mg/dia (Socil Evialis Nutrição Animal, Indústria Brasileira) e água à vontade.

Os animais permaneceram em jejum até 12 horas para alimento sólido e seis horas para líquidos. Para acesso venoso foi utilizada a veia marginal da orelha direita. Os fármacos utilizados para a anestesia foram: sulfato de atropina $(0,04 \mathrm{mg} /$ $\mathrm{kg}$ ) intramuscular (IM); cloridrato de ketamina (7,8 mg/kg) IM; cloridrato de xilazina $(2,2 \mathrm{mg} / \mathrm{kg}$ ) IM; succinilcolina ( $1 \mathrm{mg}) \mathrm{IV}$; o tiopental sódico $(8 \mathrm{mg} / \mathrm{kg})$ endovenoso $(\mathrm{EV})$ foi utilizado tanto na indução quanto na manutenção do plano anestésico.

Foi realizada uma incisão abdominal para o acesso ao retroperitônio para a exposição da aorta com seus ramos terminais, e da veia cava com seus ramos tributários. A anticoagulação foi feita com heparina sódica (350 UI/kg). A aorta Foi puncionada para introdução de cateter tipo Pig-tail para a realização da aortografia torácica, e introduzida bainha curta 5F pela técnica de Seldinger, introdução de fio guia teflonado 0,035"x $145 \mathrm{~cm}$ com ponta em “J”, o sistema de liberação foi apoiado no fio guia. A endoprótese foi liberada logo após a emergência da artéria subclávia esquerda, sob visão fluoroscópica. Feita arteriorrafia com fio de polipropileno arterial 6.0. O procedimento venoso foi realizado em seqüência, com punção da veia Ilíaca comum direita, introdução da bainha curta $5 \mathrm{~F}$ pela técnica de Seldinger, fez-se flebografia para orientação radiológica e delimitação das veias renais, limite proximal do dispositivo. Recolocação de fio guia teflonado e introdução do dispositivo e liberação da endoprótese seguida de flebografia de controle pelo próprio sistema liberador retraído (Figura 2). A fleborrafia foi feita com fio de polipropileno 7.0. A reversão da anticoagulação foi realizada com cloridrato de protamina, $1 \mathrm{ml}$ para cada 1000 UI de heparina sódica. Síntese da parede abdominal por planos.

Os animais permaneceram inicialmente próximos ao centro cirúrgico, até a redução do nível anestésico. Posteriormente foram transferidos para o alojamento conjunto com boas condições, recebendo água "ad libitum", e alimentação adequada. Foram mantidos o antiinflamatória por três dias (Flunixin meglumine $50 \mathrm{mg} / \mathrm{dia}$ ) e antibiótico por sete dias (enrofloxacina $1 \mathrm{ml} / 20 \mathrm{~kg})$.

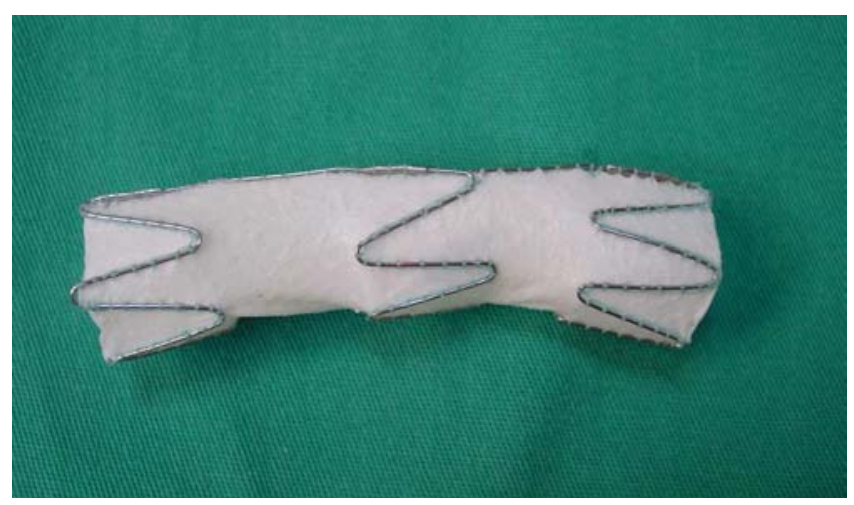

Figura 1 - Stent de jugular de bovino processada pelo método L-Hydro. 
A morte dos animais foi induzida 60 dias após o implante com injeção de cloreto de potássio $10 \%$, na dose de 20 $\mathrm{ml}$ "in bolus". Os segmentos arterial e venoso foram ressecados em bloco e fixados em formol a $10 \%$.

Foram elaborados escores de comparação obedecendo a determinados aspectos. Aspecto fibrose e aderência a estruturas adjacentes: 0- nenhuma; 1 - moderada; e 2 - fibrose intensa. Aspecto perviedade: 0- oclusão; um - trabeculações na luz (parcial); dois - total. Aspecto incorporação: 0 - nenhuma; um - incorporação parcial; dois - totalmente incorporada.

Foram realizados cortes microscópicos axiais nos segmentos em contato direto com os anéis (intra-aneis), nos segmentos entre dois anéis (inter-aneis). Os segmentos foram incluídos em blocos de parafina submetidos a cortes histológicos com $4 \mu \mathrm{m}$ de espessura e corados com hematoxilina-eosina. Adotamos o seguinte critério de quantificação dos elementos histológicos para graduação da reação inflamatória: leve - menor que 30\%; moderada - entre 30 e $70 \%$; e grave - acima de $70 \%$.

\section{RESULTADOS}

Todas as endopróteses foram liberadas com sucesso, e os animais permaneceram vivos até o sacrifício, um animal apresentou abscesso na parede abdominal que regrediu com tratamento clínico. Três animais apresentaram linfocele, dois apresentaram granuloma na parede distal e externa da peça.

Não foi observada nenhuma oclusão tanto no sistema arterial quanto no venoso, porém uma amostra da aorta apresentou discreta estenose (10\%) (Figura 3) enquanto a maioria das peças venosas $(60 \%)$ apresentou perviedade parcial (Figura 4 ). No aspecto aderência a aorta se mostrou livre em $100 \%$ dos casos, comparado com a veia que apresentou um percentual de $60 \%$ (Tabela 1). Em relação ao grau de incorporação $100 \%$ das próteses implantadas na cava encontravamse totalmente aderidas contrastando com a aorta onde somente $60 \%$ estavam totalmente aderidas (Tabela 1 ).

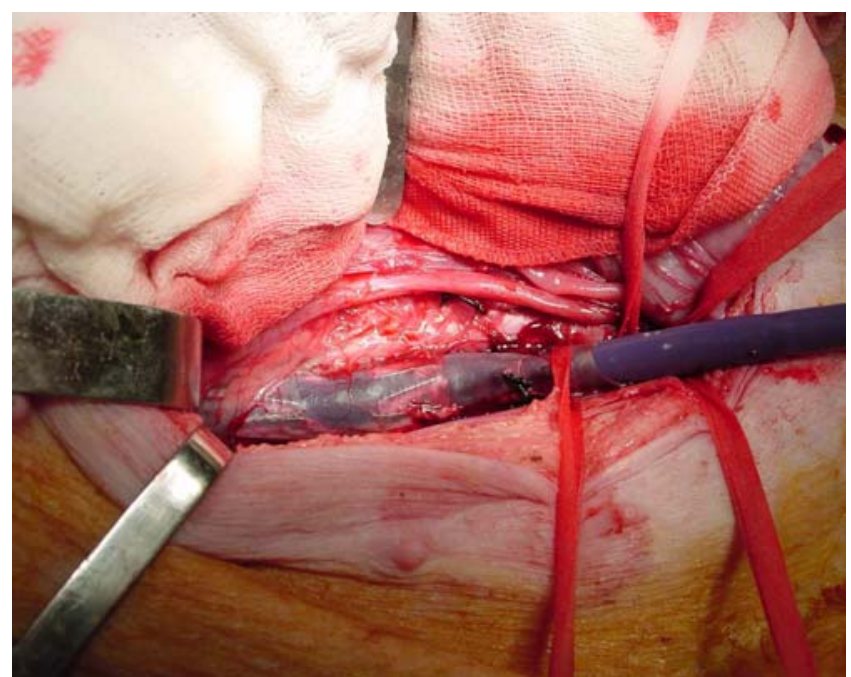

Figura 2 - Sistema liberador introduzido na veia cava através da veia Ilíaca direita. Exibindo os anéis já instalados na cava.

\section{Microscopia}

À luz da microscopia foram encontrados processos inflamatórios crônicos com reação granulomatosa tipo corpo estranho, em variados graus, em todas as peças examinadas nos dois sistemas. O sistema arterial apresentou $80 \%$ de reação inflamatória em grau leve com tendência para as peças retiradas do espaço inter-anéis, apesar de o somatório total ser maior nos espaços intra-anelares. Já no grupo venoso $60 \%$ das peças apresentaram uma forma grave de reação inflamatória, com leve tendência para as peças retiradas do espaço intraanelares, acompanhando o somatório total. Na artéria a predominância da reação tecidual foi encontrada na camada íntima, 90\% dos casos, já a camada mais acometida no sistema venoso foi a média, $80 \%$ das peças. (Figura 5)

\section{DISCUSSÃO}

O suíno está entre os animais mais comumente usados atualmente como modelo para doença aterosclerótica. Eles preenchem as seguintes características: evidência de doença natural na espécie; fácil induzibilidade da doença com dieta aterogênica; distribuição temporo-espacial da doença similar à espécie humana ${ }^{13}$. Os suínos se assemelham ao homem tanto histológica quanto histopatologicamente em relação aos vasos periféricos e às placas de aterosclerose. Apesar de apresentarem maior tendência à coagulabilidade com um sistema fibrinolítico não tão ativo como o do cão, os suínos são os modelos de escolha para a pesquisa de Stents farmacológicos em artérias coronárias. Nossa opção pelos suínos da raça Landrace foi baseada na semelhança morfológica, histológica, anatômica e na facilidade de aquisição dos mesmos. A diferença ponderal não se tornou óbice frente ao prazo estipulado para o sacrifício. Mesmo com as características referidas na literatura de uma maior tendência à hipercoagulação, não foi observado nenhum caso de trombose vascular tanto no lado arterial quanto no lado venosa, fazendo-nos crer que o dispositivo implantado apresenta baixa trombogenicidade.

A morte súbita, as complicações clinicas (morte não associada ao procedimento, febre, intolerância, alterações

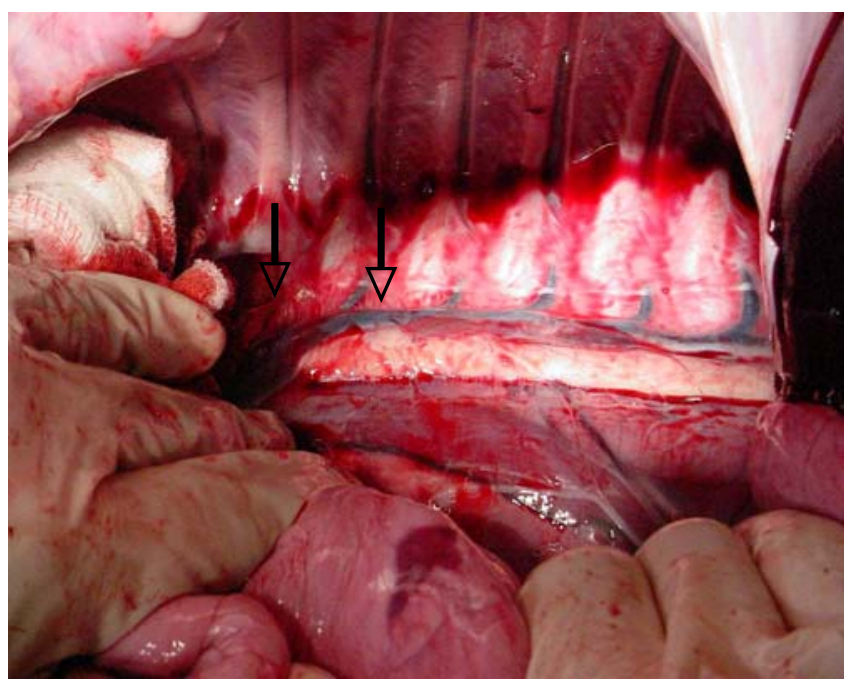

Figura 3 - Discreta estenose na projeção do local de implante do Stent na aorta. 
Tabela 1 - Macroscopia das peças operatórias da artéria aorta e veia cava dos suínos.

\begin{tabular}{lcccccc}
\hline Ident. do animal & \multicolumn{2}{c}{ Aderência } & \multicolumn{2}{c}{ Perviedade } & \multicolumn{2}{c}{ Incorporação } \\
\cline { 2 - 6 } & Aorta & Cava & Aorta & Cava & Aorta & Cava \\
\hline $79 \mathrm{Am}$ & 0 & 1 & 2 & 1 & 1 & 2 \\
$99 \mathrm{Am}$ & 0 & 0 & 2 & 1 & 2 & 2 \\
$100 \mathrm{Am}$ & 0 & 0 & 2 & 1 & 1 & 2 \\
$72 \mathrm{Vd}$ & 0 & 0 & 2 & 2 & 1 & 2 \\
$73 \mathrm{Vd}$ & 0 & 0 & 2 & 2 & 2 & 2 \\
$17 \mathrm{Vd}$ & 0 & 2 & 2 & 1 & 2 & 2 \\
$61 \mathrm{Vd}$ & 0 & 0 & 2 & 2 & 2 & 2 \\
$64 \mathrm{Vd}$ & 0 & 2 & 2 & 1 & 2 & 2 \\
$67 \mathrm{Vd}$ & 0 & 0 & 2 & 2 & 2 & 2 \\
$69 \mathrm{Vd}$ & 0 & 1 & 2 & 1 & & 2 \\
\hline
\end{tabular}

Aderência perivascular: 0 -nenhuma; 1 - moderada; 2 -intensa.

Perviedade: 0 -oclusão; 1 - parcial; 2 -total.

Incorporação ao vaso: 0 - nenhuma; 1 - parcial; 2 -total.

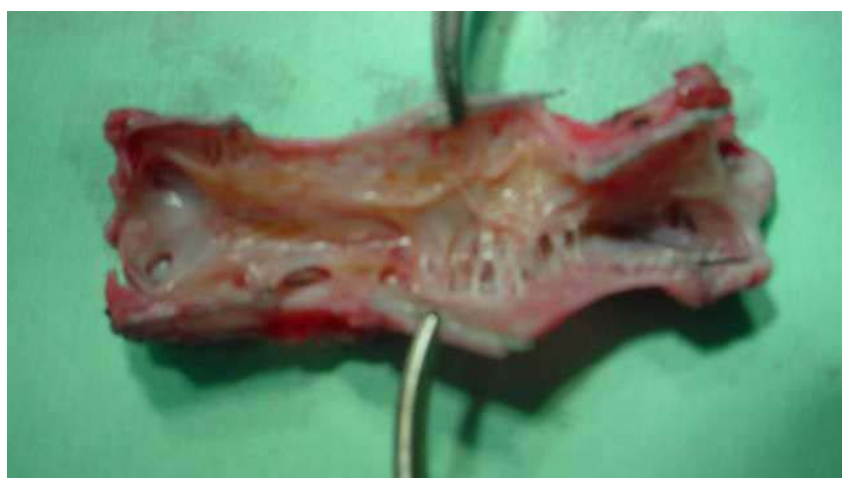

Figura 4 - Veia cava em corte longitudinal exibindo trabéculas em seu interior, com perviedade parcial.

neurológicas), a trombose do Stent; o infarto, a isquemia distal, a inflamação peri-Stent; a perda do endotélio; fibrina em quantidade e a estenose do vaso são complicações encontradas na literatura ${ }^{14}$. No nosso estudo não ocorreu nenhuma morte precoce, as complicações clínicas ocorreram em $60 \%$ dos casos, sendo que relacionadas diretamente ao ato cirúrgico, só uma, a liberação inadequada de um Stent no sistema venoso.

Estudos com Stents farmacológicos em artérias coronárias utilizam avaliações do grau de inflamação, tipo de reação e os locais de alteração das camadas do vaso, além da relação do contato com o metal ${ }^{13-15}$. Nosso experimento procurou avaliar e comparar a resposta tecidual das artérias e veias após a introdução de um dispositivo utilizando-se para tal uma escala subjetiva da reação inflamatória nos locais em contato direto com o metal do anel e nos locais entre os anéis, além de verificar nas camadas do vaso a mais comprometida.

Há um padrão para avaliar os níveis aceitáveis de reação inflamatória e para analisar o aparecimento, a aceleração da lesão vascular, ou a estenose com uso de Stents farmacológicos. A lesão vascular é aceitável em até $20 \%$ dos cortes, e é avaliada quando decorre do ato mecânico ou pelo efeito do material observado ${ }^{15}$.

Nosso estudo demonstrou que houve reação inflamatória crônica tipo corpo estranho em todas as lâminas, sendo que nas artérias, a maioria (80\%) foi considerada leve, e apresentou maior incidência nas regiões inter-anelares, diferente do setor venoso onde $60 \%$ foram consideradas graves e com discreta tendência nas regiões intra-anelares. As trabeculações intravasculares encontradas nas veias caracterizaram a perviedade parcial e constituíram $60 \%$ das peças examinadas, entretanto nas artérias só foi observado um caso de estenose discreta. Não obstante ter sido encontrada reação inflamatória em todas as peças, artérias e veias, os níveis aceitáveis de lesão vascular foram ultrapassados em ambos, mesmo no setor arterial onde foi mais branda.

A falência do enxerto no período pós-operatório imediato normalmente é considerada erro técnico, o que não ocorreu no estudo. A falência do enxerto pode já estar determinada a partir do momento de sua retirada (durante sua dissecção), pela exposição do enxerto à líquidos com baixa pressão oncótica, pela ruptura da vasa vasorum, no armazenamento em condições hipotérmicas, conseqüente ao estiramento no preparo para a anastomose, eversão, leito distal inadequado, dissecção da anastomose distal ${ }^{16-19}$.

O dispositivo utilizado em nosso experimento procurou reduzir os fatores produtores de falência, através da microdissecção no preparo do enxerto de jugular de bovino, evitando o trauma mecânico na veia (distenção), evitando a hipotermia e utilizando o processamento pela técnica L-hydro que combina a adição de substancia antiinflamatória e antitrombótica na parede do dispositivo. Ainda sim se somaram a estes cuidados o uso de antibióticos e antiinflamatórios injetáveis até o sétimo dia de pós-operatório.

Sterpeti em seu trabalho, focalizado na resposta biológica de um enxerto venoso autólogo exposto ao sistema arterial (alta pressão), estudou suas alterações biológicas, e logo a seguir os reimplantou no sistema venoso (baixa pressão). Concluiu que a hiperplasia miointimal, resultante do primeiro estagio do trabalho e a regressão no segundo estagio eram regulados por fatores de crescimento e substancias inibidoras dependentes do estimulo hemodinâmico ${ }^{20,21}$. A velocidade do fluxo sangüíneo relaciona-se diretamente com a força de cisalhamento do sangue sobre a camada íntima e o vaso pode responder de vários modos as fatores mecânicos ${ }^{22}$. 


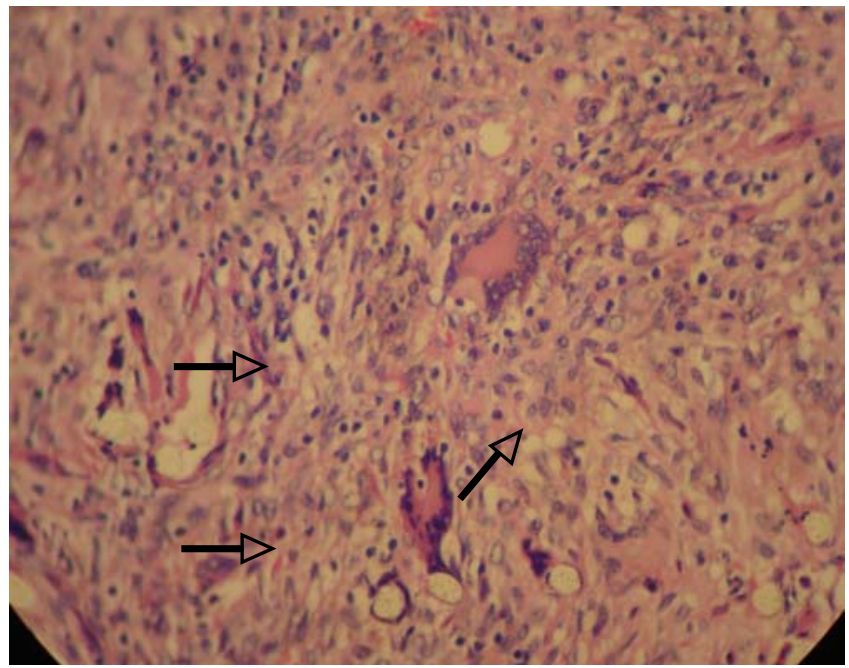

Figura 5 - Processo inflamatório crônico com célula gigante tipo "Corpo Estranho" englobando uma imagem negativa do corpo estranho (seta inf), Presença de células mononucleares (seta sup.), eosinófilos e fibroblastos (células com núcleos alongados), (seta a direita) HE $40 x$.

Em nosso estudo, a presença da estrutura de aço do dispositivo limitava qualquer alteração tanto na dimensão longitudinal quanto na circunferencial, as alterações proliferativas foram bastante exíguas no sistema arterial, ao contrario do sistema venoso onde formações trabeculares conferiam importante comprometimento da luz venosa em $60 \%$ das amostras.

Os auto-enxertos são considerados os melhores para utilização, não apresentam o incômodo da incompatibilidade gênica, porém, considerando a doença aterosclerótica como sistêmica, são de disponibilidade bem limitada. Aloenxertos, também são de pouca disponibilidade. Neste aspecto os Xenoenxertos passam a ser alvo de estudo como vantagem de utilização. Para isto, os estudos têm evoluído para os métodos de processamento e preservação compatíveis e aplicáveis a área médica. Baseados nesta característica de disponibilidade, nosso experimento procurou estudar e comparar as respostas biológicas de um xenoenxerto processado pelo método L-hydro, quando implantado na veia e na artéria.

Tabela 2 - Local de reação inflamatória com relação à camada estrutural da artéria e da veia.

\begin{tabular}{lcc}
\hline Identificação & Artéria Aorta & Veia Cava \\
\hline $79 \mathrm{Am}$ & $\mathrm{I}$ & $\mathrm{M}-\mathrm{A}$ \\
$99 \mathrm{Am}$ & $\mathrm{I}-\mathrm{A}$ & $\mathrm{M}$ \\
$100 \mathrm{Am}$ & $\mathrm{I}$ & $\mathrm{M}$ \\
$72 \mathrm{Vd}$ & $\mathrm{I}-\mathrm{M}$ & $\mathrm{M}-\mathrm{A}$ \\
$73 \mathrm{Vd}$ & $\mathrm{I}$ & $\mathrm{I}$ \\
$17 \mathrm{Vd}$ & $\mathrm{I}$ & $\mathrm{I}$ \\
$61 \mathrm{Vd}$ & $\mathrm{I}$ & $\mathrm{M}-\mathrm{A}$ \\
$64 \mathrm{Vd}$ & $\mathrm{I}$ & $\mathrm{M}$ \\
$67 \mathrm{Vd}$ & $\mathrm{I}$ & $\mathrm{M}$ \\
$69 \mathrm{Vd}$ & $\mathrm{A}$ & $\mathrm{M}$ \\
\hline
\end{tabular}

I: Camada Intima; M: Camada Média ou Muscular; A: Camada Adventícia.
Apesar da disponibilidade como vantagem, este dispositivo esbarra na discordância genética entre o animal escolhido como o mais habilitado. Alguns fatores foram analisados, e entre vantagens e desvantagens, o suíno foi o eleito pela dimensão mais próxima da espécie humana, e pela aproximação histológica dos vasos. Duas linhas de ação podem ser delineadas, a primeira agindo na fonte doadora com a criação de animais doadores já compatibilizados imunologicamente a criação de suínos transgênicos por inoculação de material genético no ovo fertilizado ou na célula germinativa. A outra linha de ação seria a retirada da estrutura a ser utilizada em animais normais e criar a compatibilidade imunológica através de processos químicos e físicos.

Acredita-se que a hiperplasia miointimal seja a causa mais comum de reestenose vascular, e seja resultante de lesão endotelial levando a formação de tecido fibroproliferativo e matriz extracelular a partir de células musculares lisas. Ip sugere em seu trabalho que, a reestenose é uma forma acelerada de doença aterosclerotica primaria, seria uma lesão aterosclerotica tipo três, apresenta como característica uma lesão medial profunda, e é predominantemente resultante do procedimento endovascular ${ }^{23}$. Na reestenose conseqüente ao implante do stent há uma relação direta de causa e efeito entre a gravidade da lesão e o espessamento miointimal ${ }^{24-26}$. As formações trabeculares encontradas na luz venosa correspondem a um aumento da resposta cicatricial, à extensão da área recoberta, e do tipo de xenoenxerto utilizado. Já no território arterial, só um caso de estenose foi visto, mesmo assim bem discreta, sem irregularidades, não trazendo nenhuma repercussão clínica.

A maioria dos trabalhos sobre hiperplasia miointimal após angioplastia com Stent sugere que a proliferação das células musculares lisas ocorre dentro do primeiro mês pósintervenção e vários fatores são envolvidos neste processo ${ }^{27}$ e podem ser a causa da proliferação celular e conseqüiente estenose $^{28}$. Neste aspecto, Sullivan et al, confirmam que a manutenção da lâmina elástica interna é um fator importante para a prevenção da hiperplasia miointimal ${ }^{27}$. Em nosso trabalho, optamos pela utilização da estimativa aproximada do diâmetro do vaso e escolha de um dispositivo auto-expansivo compatível, com memória, e, por conseguinte, a não indicação de dilatação elástica interna. Acreditamos que esta linha de ação evitou uma possível hiperplasia miointimal.

A extensão da resposta no local do implante depende do tipo de dispositivo, em particular do material da tela metálica (aço, nitinol), presença de cobertura (veia, poliéster, PTFE) ${ }^{29,30}$. Há estudos sugerindo que Stents recobertos são mais trombogênicos que Stents simples de metal, e a endotelização é retardada por alguns tipos de Stents recobertos levando a uma potencial oclusão trombótica ${ }^{31}$. O politetraetileno terephtalato e o poliéster são mais trombogênicos e imunogênicos que o PTFE e outros, principalmente em vasos de pequeno calibre, 2,33 .

Marty et al, em seu estudo comparativo com a introdução de dispositivos recobertos com uretano policarbonado e recobertos com poliéster, em suínos demonstrou maior grau de aderência nos primeiros, e aderência débil nos últimos. Faz referencia também do grau de reação tecidual com extensa granulação na região entre a luz do vaso e a face externa do dispositivo invadindo os poros da cobertura da prótese como causa da boa aderência ${ }^{34}$. Em nosso estudo, o grau de 
adesividade do dispositivo ao vaso venoso, de um modo geral foi melhor quando comparado à artéria. Nesta última, a adesividade era total, porém de caráter débil e esta característica esta na razão direta do grau de processo inflamatório desenvolvido pelo tecido vascular. No trabalho, dentre as veias, três $(30 \%)$ foram consideradas descoláveis ao manuseio, e sete $(70 \%)$ se apresentaram firmemente aderidas. Em contrapartida, nas artérias, sete $(70 \%)$ se apresentaram fragilmente aderidas, descolando-se facilmente ao manuseio, e só três $(30 \%)$ se encontravam aderidas firmemente. No estudo ainda foi observado o comprometimento preferencial do processo infamatório na camada intima das artérias $(90 \%)$, comparado ao comprometimento da camada média da veia $(80 \%)$.

A prótese biosintética composta pela armação de aço, revestida por veia jugular de bovino, tratada pela técnica LHydro apresenta uma resposta inflamatória granulomatosa tipo corpo estranho em ambos os sistemas, porém foi mais acentuada no leito da veia cava inferior em relação ao leito da aorta. O grau de incorporação do dispositivo a parede do vaso é diretamente proporcional ao grau de resposta inflamatória produzida pela prótese, sendo mais facilmente descolável na artéria onde a reação era predominantemente leve, e mais firmemente aderida na veia onde a reação era predominantemente grave. A resposta inflamatória, na artéria, acomete mais a camada íntima, diferente da veia onde o acometimento é maior na camada média. Em relação ao contato dos anéis com a luz do vaso, encontramos nos grupos arterial e venoso, maior reatividade tecidual nas áreas intra-aneis, sendo mais intensa no primeiro grupo em relação ao segundo. E finalmente concluímos que a prótese biosintética estudada apresenta melhor biocompatibilidade quando de sua implantação na aorta torácica, em relação a sua implantação na veia cava inferior de suínos.

\begin{abstract}
Background: To evaluate and compare the tissue response, in swine, to a biosynthetic stent-graft when implanted in both thoracic aorta and inferior vena cava. Method: It was used a self-expanding stainless stent, covered by segment of bovine jugular veins, processed by the method L-hydro, and delivered by Taheri-Leonhardt system (Florida, USA). The implants were done in the descending thoracic aorta, and in the infra-renal vena cava of 10 swines. Sixty days after, the endoprosthesis were removed and analyzed under macro and microscopic view. The following parameters were analyzed: patency, incorporation to the vessel wall, type of inflammatory reaction, tissue response concerning the layer of the vessel as for the contact with the ring steel. Results: All implanted stent-grafts were patent, and incorporated to the vessel wall. Six presented fibrous bars, and four presented perivascular fibrosis at the venous section. At the arterial section, only one prosthesis developed a very small stenosis, without perivascular fibrosis. We observed chronic inflammatory reaction with a foreign body granulomatous response in 100\% of the samples, the medium layer was the more prevalent at the vein section, while the intima layer was more constant at the artery, venous incorporation was stronger than artery incorporation, and tissue response was enhanced in the inner contact between the vessel wall and the ring steel. Conclusion: The prosthesis in study presented low thrombogenicity in both systems. It was also present, larger tissue response and low biocompatibility at the venous system, and better biocompatibility at the arterial system.
\end{abstract}

Key words: Blood vessel prosthesis implantation ; Stents; Jugular veins; Vena cava, inferior/surgery; Aorta thoracic/surgery; Vascular patency; Material testing; Cattle/surgery; Swine/surgery; Comparative Study.

\section{REFERENCIAS}

1. Cooper JD, Pearson FG, Patterson GA, Todd TR, Ginsberg RJ, Goldberg M, Waters P. Use of silicone stents in the management of airways problems. Ann Thorac Surg. 1989;47(3):371-8.

2. Dotter CT. Transluminally-placed coilspring endarterial tube grafts. Long-term patency in canine popliteal artery. Invest Radiol. 1989;4(5):329-32.

3. Fiorelli RKA. Biocompatibilidade de stents metálicos auto-expansivos recobertos na Traquéia - Estudo experimental em cães [dissertação]. Rio de Janeiro (RJ): Universidade do Rio de Janeiro; 2004.

4. Rajasinghe HA, Tzilinis A, Keller T, Schafer J, Urrea S. Endovascular exclusion of popliteal artery aneurysms with expanded polytetrafluoroethylene stent-grafts: early results. Vasc Endovascular Surg. 2006;40(6)460-6.

5. Bush HL Jr, McCabe ME, Nabseth DC. Functional injury of vein graft endothelium. Role of hypothermia and distension. Arch Surg. 1984;119(7):777-74.
6. Bush RL, Lin PH, Lumsden AB. Endovascular treatment of the thoracic aorta. Vasc Endovascular Surg. 2003;37(6):399-405.

7. Espinosa G, Parodi JC, Filippo R, Tourinho PP, Oliveira JB, Pérez Barquero RA, et al. Endoprótese vascular recoberta ("stentgraft") no tratamento das fístulas arterio-venosas traumáticas. Rev Angiol Cir Vasc. 1996;5(2):63-6.

8. George PJ, Irving JD, Mantell BS, Rudd RM. Covered expandable metal stent for recurrent tracheal obstruction. Lancet. 1990;335(8689):582-4.

9. Dolmatch BL. Healing response to vascular stent graft. J Vasc Surg. 2000;31(6):1285-90.

10. Dolmatch BL, Dong YH, Trerotola SO, Hunter DW, Brennecke LH, Labounty R. Tissue response to covered Wallstents. J Vasc Interv Radiol. 1998;9(3):471-8.

11. Gahtan V, Peyman JA, Sumpio BE. Understanding molecular biology. Semin Vasc Surg. 1988;11(3):125-33.

12. Gomes-Jorge J, Venbrux AC, Magee C. Percutaneous deployment of a valved bovine jugular vein in the swine system: a potential treatment for venous insufficiency. J Vasc Interv Radiol. 2000;11(7):931-6. 
13. Narayanaswamy M, Wright KC, Kandarpa K. Animal models in atherosclerosis, restenosis, and endosvascular graft research. J Vasc Interv Radiol. 2000;9(2):5-17.

14. Schwartz RS, Edelman ER, Carter A, Chronos NA, Rogers C, Robinson KA, et al. Preclinical evaluation of drug-eluting stents for peripheral applications: recommendations from an expert consensus group. Circulation. 2004;110(16):2498-505.

15. Schwartz RS, Edelman ER, Carter A, Chronos NA, Rogers C, Robinson KA, et al. Drug-eluting stents in preclinical studies: recommended evaluation from consensus group. Circulation. 2002;106(14):1867-73.

16. Angelini GD, Breckenridge IM, Psaila JV, Williams HM, Hemnderson AH, Newby AC. Preparation of human saphenous vein for coronary artery bypass grafting impairs its capacity to produce prostacyclin. Cardiovasc Res. 1987;21(1):28-33.

17. Angelini GD, Bryan AJ, Williams HM, Morgan R, Newby AC. Distention promotes platelet and leukocyte adhesion and reduces short-term patency in pig arteriovenous bypass grafts. J Thorac Cardiovasc Surg. 1990;99(3):433-9.

18. Bryan AJ, Angelini GD. The biology of saphenous vein graft occlusion: etiology and strategies for prevention. Curr Opin Cardiol. 1994;9(6):641-9.

19. Cox JL, Chiasson DA, Gotlieb AI. Stranger in a strange land: the pathogenesis of saphenous vein graft stenosis with emphasis on structural and functional differences between veins and arteries. Progr Cardiovasc Dis. 1991;34(1):45-68.

20. Gibbons GH, Dzau VJ. The emerging concept of vascular remodeling. New Engl J Med. 1994;330(2):1431-8.

21. Sterpetti AV, Cucina A, Lepidi S, Randone B, Corvino V, D'Angelo LS, Cavallaro A. Formation of myointimal hyperplasia and cytokine production in experimental vein grafts. Surgery. 1998;123(4):461-9.

22. Dobrin PB, Littooy FN, Endean ED. Mechanical factors predisposing to intimal hyperplasia and medial thickening in autogenous vein grafts. Surgery. 1989;105(3):393-400.

23. Ip JH, Fuster V, Badimon L, badimon J, Taubman MB, Chesebro JH. Syndrome of accelerated atherosclerosis: role of vascular injury and smooth muscle cell proliferation. J Am Coll Cardiol. 1990;15(7):1667-87.

24. Clowes AW, Clowes MM, Fingerle J, Reidy MA. Regulation of smooth muscle cell growth in injured artery. J Cardiovasc Pharmacol. 1989;14 (Suppl 6):S12-S15.

25. Phillips-Hughes J, Kandarpa K. Restenosis: pathophysiology and preventives strategies. J Vasc Interv Radiol. 1996;7(3):32133 .
26. Waller BF, Pinkerton CA, Orr CM, Slack JD, VanTassel JW, Peters T. Morphological observations late (greater than 30 days) after clinically successful coronary balloon angioplasty. Circulation. 1991;83 (2 Suppl):I128-41.

27. Sullivan TM, Ainsworth SD, Langan EM, Taylor S, Synder B, Cull D, et al. Effect of endovascular stent strut geometry on vascular injury, myointimal hyperplasia, and restenosis. J Vasc Surg. 2002;36(1):143-9.

28. Schwartz RS, Murphy JG, Edwards WD, Camrud AR, Vliestra RE, Homes DR. Restenosis after balloon angioplasty. A practical proliferative model in porcine coronary arteries. Circulation. 1990;82(6):2190-200.

29. Ramdomski MW, Palmer RM, Moncada S. The anti-aggregating properties of vascular endothelium: interactions between prostacyclin and nitric oxide. Br J Pharmacol. 1987;92(3):639-46.

30. Xenos ES, Freeman M, Stevens S, Cassada D, Pacanowski J, Goldman M. Covered stents for injuries of subclavian and axillary arteries. J Vasc Surg. 2003;38(3):451-4.

31. Amar AP, Teitelbaum GP, Giannotta SL, Larsen DW. Covered stent-graft repair of the brachiocephalic arteries: technical notes. Neurosurgery. 2002;51(1)247-52; discussion 252-3.

32. Cejna M, Virmani R, Jones R, Bergmeister H, Losert U, Xu Z, et al. Biocompatibility and performance of the Wallstent and several covered stents in a sheep iliac artery model. J Vasc Interv Radiol. 2001;12(3):351-8.

33. Ferko A, Páral J, Raupach J, Chovanec V, Krajina A, Mericka P, et al. Autologous vein stent-graft: feasibility study. J Vasc Interv Radiol. 2000;11(1):111-4.

34. Marty B, Leu AJ, Muccidio A, von Segesser LK. Biologic fixation of polyester versus polyurethane-covered stents in a porcine model. J Vasc Interv Radiol. 2002;13(6):601-7.

Como citar este artigo:

Chouin CLM, Riguetti Pinto CRR, Lopez GE. Endoprótese revestida de jugular preservada de bovino: estudo comparativo da resposta tecidual em aorta torácica descendente e veia cava inferior de suínos. Rev Col Bras Cir. [periódico na Internet] 2008; 35(4). Disponível em URL: http://www.scielo.br/rcbc

Endereço para correspondência:

Celso Luiz Muhlethaler Chouin

Av. Jose Luiz Ferraz, 55/501 - Recreio dos Bandeirantes

22790- 587 - Rio de Janeiro - RJ

Tel: (21) 9988-2658

E-mail: celsocho6@hotmail.com 